\title{
Expression and clinical implications of estrogen receptors in thoracic malignancies: a narrative review
}

\author{
Giulia Pinton, Beatrice Manzotti, Cecilia Balzano, Laura Moro \\ Department of Pharmaceutical Sciences, University of Piemonte Orientale, 28100 Novara, Italy \\ Contributions: (I) Conception and design: None; (II) Administrative support: None; (III) Provision of study materials or patients: None; (IV) \\ Collection and assembly of data: C Balzano, B Manzotti; (V) Data analysis and interpretation: G Pinton, L Moro; (VI) Manuscript writing: All \\ authors; (VII) Final approval of manuscript: All authors. \\ Correspondence to: Giulia Pinton; Laura Moro. Department of Pharmaceutical Sciences, University of Piemonte Orientale, L.go Donegani, 2, 28100 \\ Novara, Italy. Email: giulia.pinton@uniupo.it; laura.moro@uniupo.it.
}

\begin{abstract}
Thoracic malignancies represent a significant global health burden with incidence and mortality increasing year by year. Thoracic cancer prognosis and treatment options depend on several factors, including the type and size of the tumor, its location, and the overall health status of patients. Gender represents an important prognostic variable in thoracic malignancies. One of the greatest biological differences between women and men is the presence of female sex hormones, and an increasing number of studies suggest that estrogens may play either a causative or a protective role in thoracic malignancies. Over the past 60 years since the discovery of the first nuclear estrogen receptor (ER) isoform $\alpha$ and the almost 20 years since the discovery of the second estrogen receptor, ER $\beta$, different mechanisms governing estrogen action have been identified and characterized. This literature review reports the published data regarding the expression and function of ERs in different thoracic malignancies and discuss sex disparity in clinical outcomes. From this analysis emerges that further efforts are warranted to better elucidate the role of sex hormones in thoracic malignancies, and to reduce disparities in care between genders. Understanding the mechanisms by which gender-related differences can affect and interfere with the onset and evolution of thoracic malignancies and impact on response to therapies could help to improve the knowledge needed to develop increasingly personalized and targeted treatments.
\end{abstract}

Keywords: Estrogen receptors; thoracic malignancies; precision medicine

Submitted Jun 22, 2020. Accepted for publication Dec 31, 2020.

doi: $10.21037 /$ jtd-20-2277

View this article at: http://dx.doi.org/10.21037/jtd-20-2277

\section{Introduction}

Thoracic malignancies (including lung cancers, malignant mesotheliomas, esophageal and thymus cancers) represent the leading cause of cancer related death, whose incidence is dramatically increasing worldwide due to population ageing and to lifestyle risk factors such as smoking, obesity and sedentary behavior. Unfortunately, the prognosis for these tumors is poor and treatment options are limited. Although distinct studies have described gender differences in the incidence $(1,2)$ and prognosis for several types of cancer, and in the psychosocial factors important in their medical management, relatively little is known about the causes.

$\mathrm{X}$-linked genes, hormones and environmental factors act in a gender-specific manner. Several studies have suggested a role of $\mathrm{X}$-inactivation as a prime cause of gender differences in outcome and response to therapy of cancer. In addition, epigenetic processes, as key factor in $\mathrm{X}$-chromosome inactivation, may contribute to sex-specific metabolic phenotypes (3).

Besides disparities in anatomy and genetic, hormonal differences should be taken into account when assessing the impact of gender on disease management. Sex hormones, 


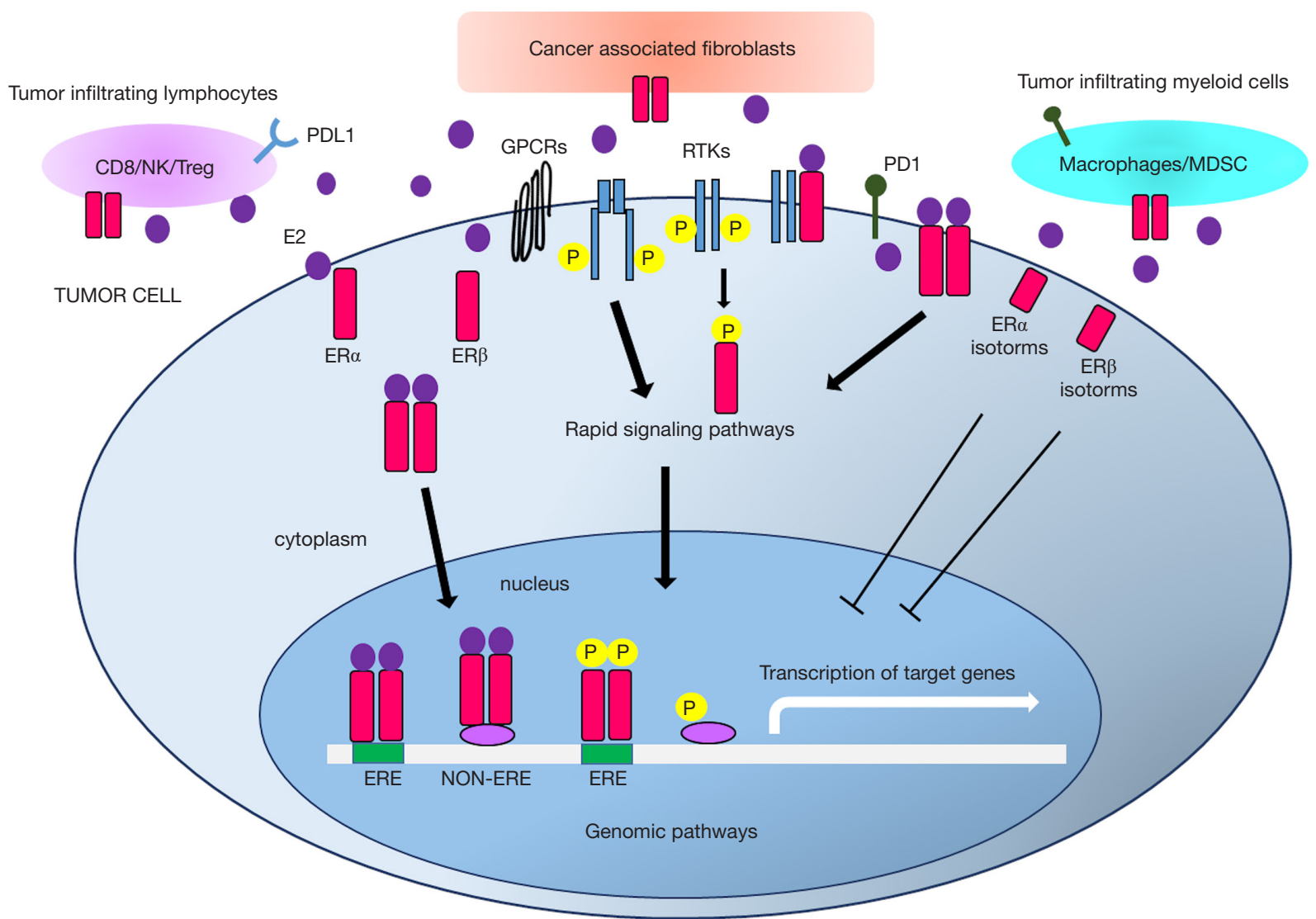

Figure 1 A schematic representation of the main rapid and genomic estrogen receptors' signaling pathways, involved in cell growth and differentiation, interaction with the tumor microenvironment and response to therapy. E2, estrogens; RTKs, receptor tyrosine kinases; P, phosphorylation; GPCRs, G protein coupled receptors; PD1, programmed cell death 1; PDL1, programmed cell death ligand 1; ER estrogen receptor; ERE, estrogen response element; Tregs, regulatory T cells; MDSC, myeloid-derived suppressor cells.

negatively or positively, affect the development of different types of cancer and determine the patients' response to therapy.

In particular, estrogens exert their functions interacting with two subtypes of estrogen receptors (ERs), ER $\alpha$ and $E R \beta$. The first characterization of tissue distribution of $E R \alpha$ and $\operatorname{ER} \beta$ transcripts, performed in rats, indicated $\operatorname{ER} \beta$ as the predominant isoform in the lung (4).

Alterations in the lung phenotype of $\mathrm{ER} \alpha$ null ( $\alpha \mathrm{ERKO})$ mice were not reported $(5,6)$. Instead, data obtained with ER $\beta$ null ( $\beta E R K O)$ mice suggested that ER $\beta$ exerts a role in basal lung homeostasis (7). These mice had reduced numbers of alveoli in lungs of female when compared with wild-type animals (7). Moreover, lungs of $\beta E R K O$ female mice exhibited reduced surfactant production, plateletderived growth factor A (PDGF-A), and granulocyte- macrophage colony-stimulating factor (GM-CSF).

ERs act by regulating transcriptional processes through dimerization and binding to specific response elements (EREs) located in the promoters of target genes or through interactions with other transcription factors (8). In addition, membrane-bound ERs activate rapid signals, which can lead both to altered functions of proteins and regulation of gene expression (Figure 1) $(9,10)$.

Because they can be modulated by small molecules, ERs are excellent druggable targets. Different therapeutic modalities dictate endocrine therapy, specifically, the selective ER modulators (SERMs), the selective ER degraders (SERDs) and aromatase inhibitors (AIs), alone or in combination therapies.

$\mathrm{ER} \alpha$ and $\mathrm{ER} \beta$ share $~ 97 \%$ similarity in their DNA binding domain (DBD) and 59\% in the ligand binding 

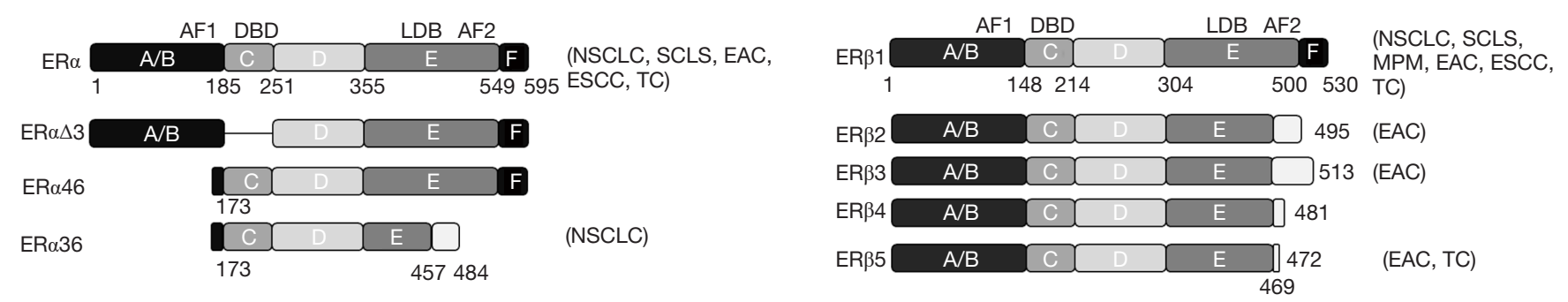

Figure 2 Structure of ER $\alpha$ and ER $\beta$ protein variants and their expression in thoracic malignancies. NSCLC, non-small cell lung cancer; SCLC, small cell lung cancer; MPM, malignant pleural mesothelioma; EAC, esophageal adeno carcinoma; ESCC, esophageal squamous cell carcinoma; TC, thymus cancer.

domain (LDB), whereas the $\mathrm{N}$ terminal domain (NTD) is merely $16 \%$ similar (8). Although the differences in the LBD are small, they are significant enough to influence the shape of the ligand-binding pocket and this has allowed the development of agonists and antagonists, which are selective for the two receptors $(11,12)$.

While ER $\alpha$ antagonists have been used for many years in the therapeutic management of breast cancer, no ER $\beta$ agonists have yet entered the clinic, despite the fact that highly selective and safe compounds have been characterized.

In addition, several variants generated either by alternative splicing (13), proteolysis (14), or alternative initiation of translation (15), have been shown to exist for ER $\alpha$ and ER $\beta$ (Figure 2). Therefore, differences in cell responsiveness to estrogens may be due to varying expression ratio of wild-type to ER variants. Along with the "classic" full-length $66-\mathrm{kDa} \mathrm{ER} \alpha$, isoforms of $61.2 \mathrm{kDa}$ $(\mathrm{ER} \alpha \Delta 3), 46 \mathrm{kDa}(\mathrm{ER} \alpha 46)$ and $36 \mathrm{kDa}(\mathrm{ER} \alpha 36)$ have been identified. $\mathrm{ER} \alpha \Delta 3$, missing exon 3, which encodes the second zinc finger of the DBD, inhibits estrogendependent transcription activation in a dominant negative fashion (16). In contrast, ER 236 retains the DBD, but lacks both transcriptional activation domains (AF-1 and $\mathrm{AF}-2)$. ERa36 localizes mainly in the cytoplasm and at the plasma membrane, and responds to both estrogens and anti-estrogens by transducing membrane-initiated signaling pathways (17). ER $\alpha 46$ lacks the A/B domain (first $173 \mathrm{~N}$-terminal amino acids) which harbors AF-1, and it is identical to the amino acids 174 to 595 of $\mathrm{ER} \alpha$ full length (13). Few studies have suggested that ERa46 inhibits the growth of tumor cell lines, suggesting that ER $\alpha 46$ could affect cancer progression.

Further to the wild-type ER $\beta$ (ER $\beta 1)$, Moore et al. characterized four spliced variants designated as ER $\beta 2$ 5 isoforms (18). The amino acid sequences differ at amino acid 469 within the LBD and extend to the C-terminus (19). Expression of ER $\beta$ variants of different lengths depends to the use of alternative transcription start sites or to alternative splicing $(18,19)$. As with ER $\alpha$, when these spliced variants are co-expressed with the ER $\beta 1$ isoform affect the response to estradiol; thus, the relative expression levels of the wild-type isoform versus ER $\beta$ variants is of significance in predicting cellular response to both estrogen and antiestrogen therapies $(20,21)$.

The overlapping and non-overlapping functions of the different ER variants and the mechanisms by which they are regulated and distributed in different subcellular compartments add another layer of complexity.

In literature, there are numerous studies that report conflicting results about the effect of estrogens on the risk, prognosis and response to therapy of thoracic cancers. In addition, in many studies, some methodological limitations emerge. In this review, we aim to provide a critical summary of the current knowledge concerning the expression, function and prognostic implications of ERs in the different thoracic malignancies listed in Figure 3. We present the following article in accordance with the Narrative Review reporting checklist (available at http://dx.doi.org/10.21037/ jtd-20-2277).

\section{Methods}

We searched for articles about Thoracic malignancies from PubMed, Medline and Google Scholar in the last 15 years, for the words estrogens, estrogen receptors, estrogen receptor isoforms. A total of 107 full texts of published peer reviewed articles were selected. 


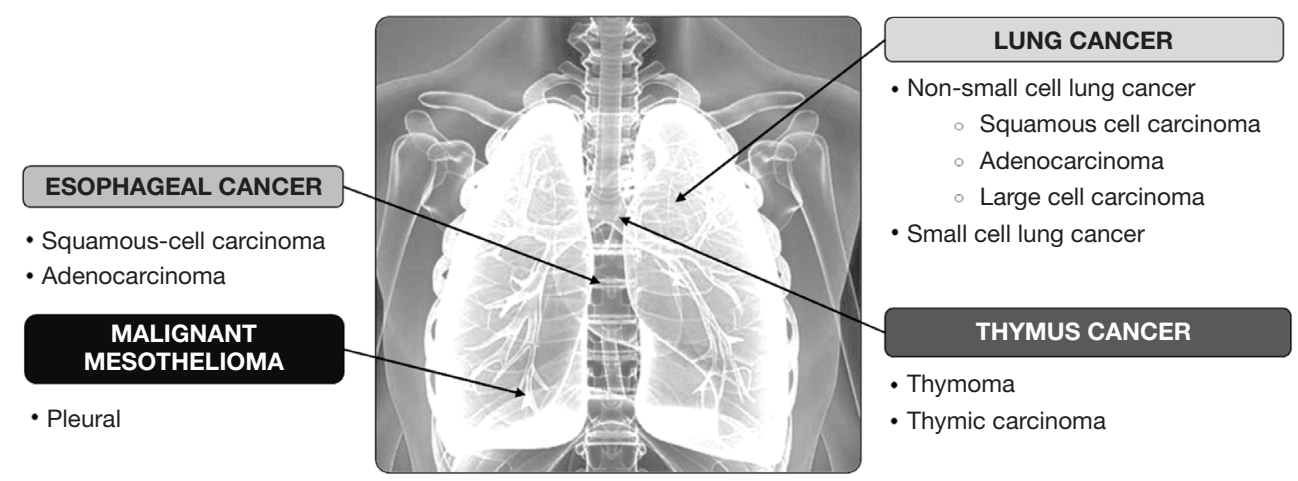

Figure 3 Thoracic malignancies discussed in this review.

\section{Non-small cell lung cancer (NSCLC)}

Subtypes: adenocarcinoma, squamous cell carcinoma (SCC), large cell carcinoma (LCC)

NSCLC is the most common, and accounts for approximately $85 \%$ of all diagnosed lung cancers. NSCLC is classified into three main subtypes, named by the type of cells detected in the tumor. Adenocarcinomas are the most common subtype of NSCLC and comprise up to $40 \%$ of lung cancer cases. Compared to other lung cancers, adenocarcinomas are not only associated with smoking, but are also diagnosed in non-smokers, in particular in women. Most adenocarcinomas occur in the lung periphery, more often they spread to the lymph nodes and beyond. In addition to adenocarcinomas, there are SCC that comprise approximately $25 \%$ to $30 \%$ of all lung cancer cases. SCC, also known as epidermoid carcinomas, most frequently arise in the central bronchi and may spread to lymph nodes, grow quite large and form a cavity. The third subtype, undifferentiated LCC, account for 10-15\% of all lung cancers. LCC have a high tendency to spread to the lymph nodes and distant sites (22).

Lung cancer has long been considered a man's disease, but over the past several decades, because of the high increase in cigarette smoking, there has been a corresponding sharp increase among women (23). Since 1998 , lung cancer death rates in women have exceeded those from breast cancer (24). However, this explanation is not perfectly satisfactory considered that up to $53 \%$ of women, while only $15 \%$ of men, who develop NSCLC were never-smoker. This suggests that, in addition to smoking, there are other risk factors that control the development of NSCLC in women versus men (25). Lung cancer in women has several different characteristics than that in men; women are more probable to have adenocarcinoma, higher risk in never-smokers, higher levels of polycyclic aromatic hydrocarbon-DNA adducts, higher levels of CYP1A1 expression, and more frequent EGFR (epidermal growth factor receptor) gene mutations (26). These studies, in line with the findings that ERs and aromatase, the key enzyme involved in the synthesis of $17 \beta$-estradiol, are frequently expressed by lung tumors, indicate a role for estrogens in determining lung cancer risk.

However, the role of ERs in NSCLC remains controversial and the mechanisms of action of ERs in NSCLC are not entirely clear. ERs are localized in both the cytoplasm and nucleus of NSCLC cells and exert both genomic and rapid non-genomic effects $(27,28)$.

The expression of $\mathrm{ER} \alpha$ and $\mathrm{ER} \beta$, as prognostic factors for NSCLC, has been reported in several studies (29-43). $\mathrm{ER} \alpha$, in NSCLC cells, was mainly located in the cytoplasm and was associated with poor prognosis. Many reports described that the nuclear localization of ER $\beta$ was predictive of better prognosis, while the cytoplasmic ER $\beta$ expression was associated with poor prognosis (44). Nonetheless, conflicting results have also been reported (43-47). In fact, it has been described that the cytoplasmic and the nuclear ER $\beta$ co-expression was correlated with low survival rate of patients, when compared to those without co-expression (48).

Significant differences in ER $\alpha$ expression rate in the NSCLC were observed using antibodies specific for the $\mathrm{N}$-terminus, C-terminus, or for the full-length protein. The detection rate of the antibody against the epitope in the $\mathrm{C}$-terminus region of $\mathrm{ER} \alpha$ was higher compared to that in the N-terminus, and was mostly located in the cytoplasm. Probably, in NSCLC, ER $\alpha$ is N-terminal deleted and lacks the nuclear localization signal (49). Few studies have 
examined the role of ER $\alpha$ variants in NSCLC, although they appear to be expressed and display specific early transcriptional effects following steroid treatment. It has been reported that ER $\alpha 36$ prevails in NSCLC specimens, while wild-type $\mathrm{ER} \alpha$ is minimally expressed. In non-tumor lung, the wild-type $\mathrm{ER} \alpha$ is quasi-absent (50).

In addition, ER $\beta$ detection rate was different using antibodies specific for the $\mathrm{N}$-terminus or the $\mathrm{C}$-terminus. Such an inconsistency may not only be due to which antibody was used, but also to differences in the methodology applied, in the heterogeneous definitions of positivity, and in several patient populations analyzed. A standardized immunohistochemistry or a different approach, such as Western blot or Real time quantitative PCR, are necessary to render the ERs useful biomarkers for NSCLC (29).

ERs have been described to influence different pathways involved in NSCLC progression, response to therapy and interaction with the tumor microenvironment. A bioinformatic analysis revealed that ERs might promote NSCLC progression by modulating the signaling cascade composed of EGFR, Notch 1 and GSK3 $\beta / \beta$-Catenin and provided new opportunities for optimizing the therapeutic scheme of NSCLC (51). In another study, it has been reported that ER $\beta$ has opposite co-expression with the multidrug resistance protein MDR1 (52). Moreover, $\mathrm{ER} \beta$ has been described to play a role in the estrogen stimulated interleukin 6 (IL6) expression in NSCLC. IL6 blockade not only results in the direct intrinsic inhibition of cancer cells proliferation, but also reeducates the lung microenvironment toward an antitumor phenotype by varying the proportion between pro-tumor and anti-tumor immune cells (53). The role of estrogens in regulating lung tumor associated stromal and immune cells is emerging. The immunosuppressive properties of estrogens deserve further investigation in NSCLC, because of the importance of immunotherapy in this disease, and the data showing that females do not benefit from immunotherapy treatment as much as men. Despite the recent reports on sex-based differences in the use of immunotherapy in NSCLC patients, current knowledge about the effect of sex hormones on immune function in this context is still in its early stages (54).

Actually, even the relationship between the hormone replacement therapy (HRT) and NSCLC is controversial. Although many studies suggested that estrogen or HRT adversely affects the prognosis of NSCLC patients (55-61), some reported that HRT decreases the risk and affects positively the prognosis (62-66). Among them, a recently published study conducted on a cohort of 75,587 women using multivariate analysis, demonstrates that current HRT use is associated with reduced risk of NSCLC compared with never users while is not associated with significant differences in all cause or disease-specific mortality (67). The physiological basis of this effect merits further exploration.

In conclusion, there is a need for further carefully designed studies with large number of patients, correctly classified for ERs expression, necessary for a more global view of the role of reproductive factors in NSCLC.

\section{Small cell lung cancer (SCLC)}

SCLC comprises about $10 \%$ to $15 \%$ of lung cancers among females and males and is strongly smoking associated. Its incidence in women is rapidly increasing (68).

Differences between sexes in SCLC prognosis were studied utilizing 161,978 patients, registered in the National Cancer Database, in the period from 2004 to 2014 (69). Limited stage (LS) or extensive stage (ES) were used to classify patients. Women were stratified according to menopausal status ( $\geq 55$ years $=$ late menopause). No significant socio-demographic differences between males and females were reported. Men were more likely to be diagnosed with ES disease than women (63\% vs. 56\%). An overall survival (OS) benefit was observed in women compared to men, for both LS (15.2 vs. 12.7 months) and ES (6.4 vs. 5.7 months). Multivariate analysis revealed that older age, postmenopausal status were associated with worse OS, for both LS and ES.

When stratified by menopausal status, women $\geq 55$ years old with both LS and ES had worse OS than younger. Older age ( $\geq 55$ years) was associated with worse OS also in men. Since in older men were observed a similar trend of worse OS compared to younger men, it's emerged that, in SCLC, age might exert a more significant influence on survival than hormonal status (69). Further studies to collect data on sex hormone levels are needed to better clarify their role in women with SCLC. Furthermore, no consistent data on ERs expression in SCLC have been published.

Only one article published, in Chinese, in 2013 (70) reports the expression of $\mathrm{ER} \alpha$ and $\mathrm{ER} \beta$, analyzed by immunohistochemistry on paraffin-embedded sections of 36 normal lung tissues and 47 cases of SCLC. Authors describe that in 36 normal lung tissues, expression of ER $\alpha$ and ER $\beta$ was $0 \%$ and $25.0 \%$ respectively, while ER $\alpha$ was expressed in 
$19.1 \%$ and $\mathrm{ER} \beta$ in $66.0 \%$ of the 47 SCLC cases.

Assuming that estrogen may play an important role in the pathogenesis of SCLC, Zeng et al. (71) stimulated by estrogen the SCLC derived MMSCLX-07 cell line to establish xenograft tumors in nude mice. They described that tumor formation rate, after stimulating MMSCLX-07 cells with $10 \mathrm{nM} 17 \beta$-estradiol, was significantly higher than stimulating MMSCLX-07 cells with normal saline. Authors conclude that estrogen may play a significant role in the pathogenesis of SCLC. However, it must be underlined that these results were obtained using only one non- authenticated and quality-tested cell line.

\section{Pleural mesothelioma}

Malignant mesothelioma is a rare form of cancer that develops in the mesothelium, a thin layer of cells lining the body's internal organs. Mesothelioma classification is based on the location where the tumor develops and the cell type. Malignant pleural mesothelioma (MPM) is the most common type, accounting for approximately $75 \%$ of all cases. Peritoneal mesothelioma is the second-most common form, responsible for about $10 \%$ of all cases, followed by the rarest pericardial and testicular mesothelioma. Asbestos exposure is the leading cause of mesothelioma (72).

Patients diagnosed with mesothelioma are more likely to be male that female with an approximate four-to-one ratio. Furthermore, one year after diagnosis, women have better survival rates than men, with $45 \%$ of women alive versus approximately $38 \%$ of men. A number of reasons have been postulated to explain the female survival advantage. Among them: women are diagnosed at a younger age and are healthier overall; they have lower asbestos exposure compared with men; and finally, hormonal differences can influence tumor prognosis $(73,74)$.

To test the role of estrogens in gender disparity, the expression of the two ER subtypes, $\mathrm{ER} \alpha$ and $\mathrm{ER} \beta$, was analyzed by immunohistochemistry in biopsies from 78 MPM patients, and pleura from healthy controls $(75,76)$. Nuclear ER $\beta$ immunoreactivity was detected in normal mesothelial cells, and in the majority of the MPM samples, although with reduced presence and intensity, compared with normal pleura. At 2 years of follow-up, the cumulative probability of survival was $80 \%$ for patients with high ER $\beta$ expression, versus $31 \%$ for patients with negative or low ER $\beta$ expression. Importantly, multivariate analysis demonstrated the prognostic relevance of ER $\beta$ expression for OS of MPM patients. Unlike other lung cancers, none of MPM or normal pleura biopsies showed positive staining for $\mathrm{ER} \alpha$, therefore, mesothelial and MPM derived cells represent a powerful model to investigate $\mathrm{ER} \beta$ functions, independently of $\mathrm{ER} \alpha$.

In vitro studies provided evidence that $\mathrm{ER} \beta$ exerts a key role in controlling the transcription of cell divisionand metabolism-related genes in MPM derived cells (77). Furthermore, a selective ER $\beta$ agonist was demonstrated to act in vivo as a chemosensitizer, increasing the antitumorigenic efficacy of cisplatin and of cisplatin/pemetrexed combination in a mouse model of MPM (78).

More recently, a retrospective single center study analyzed the role of ER $\beta$ in MPM response to the firstline chemotherapy (cisplatin/antifolate combination) (79). The study included 22 patients diagnosed with MPM between 2013 to 2016, at the Mexico's National Institute for Respiratory Disease (INER), that were characterized for ER $\beta$ expression by immunohistochemical staining.

The primary endpoint was the response to chemotherapy, according to ER $\beta$ expression, while the secondary outcomes were the OS and the PFS (progression-free survival).

Seventeen patients $(77.2 \%)$ presented high or moderate ER $\beta$ expression levels, while 5 (22.7\%) had low degree or null expression. High and moderate expression of ER $\beta$ was considered when more than $50 \%$ of the cells stained with an intensity greater than $1+$, on a scale of $0-3+$.

Response to treatment was as follow: partial response $12(54.5 \%)$, stable disease $5(22.7 \%)$, and progression 3 (13.6\%). None of the patients had a complete response. Of those who had a partial response, 9 (75\%) had moderate to high degree of ER $\beta$ expression in tumor cells, and 3 (25\%) had null or low degree of ER $\beta$ expression. Moderate and high expression of ER $\beta$ in patients with advanced MPM was associated with a tendency toward higher OS and better response to chemotherapy that resulted in longer PFS. However, due to the limited number of patients, in this study, the statistical significance was not achieved.

\section{Esophageal cancers}

\section{Subtypes: adenocarcinoma, squamous-cell carcinoma}

The two main subtypes of esophageal cancers are: esophageal adenocarcinoma (EAC), which arises from the glandular cells of the lower esophagus and is more common in the developed world, and esophageal squamouscell carcinoma (ESCC), which arises from the epithelial cells lining the upper part of the esophagus and is more 
common in the developing world (80-82). A number of less common types also occur. The risk factors for EAC include gastroesophageal reflux and obesity, smoking, and low levels of intake of vegetables. Causes of the squamous-cell type include tobacco smoking, alcohol drinking, chewing betel nut and a poor diet (83).

There is a marked male predominance for EAC with a male:female incidence ratio of 9:1. This striking gender difference does not seem to be due to the established risk factors, given that their prevalence and strength of association with EAC are similar between the two sexes (84). Even though continuing research activities are necessary to fully understand the reasons for the male predominance, sex hormonal factors, in particular exposure to estrogens seems to play a role in preventing the development of EAC.

There are no reports that compare the expression levels of ERs in esophageal cancer tissues between females and males. In contrast to the anti-tumor role for ER $\beta$ described in other cancers, some studies have reported a positive association between ER $\beta$ expression and EAC development (85).

As several isoforms of ER $\beta$, with different functions, have been described, Liu et al. (86) performed a study to characterize which isoform of ER $\beta$ was expressed in EAC. They showed that all ER $\beta$ isoforms were significantly more expressed in tumors than in their precursor lesions, suggesting a role for different ER $\beta$ variants in the maintenance and evolution of EAC. Although authors did not find a correlation between ER $\beta 1$ expression and tumor proliferative activity, they showed that it tended to have higher expression in invasive tumors, compared to tumors limited to the esophageal wall.

Another study by Kalayarasan et al. (87) evaluated the expression of $\mathrm{ER} \alpha$ and $\mathrm{ER} \beta$ in EAC at different tumor stage, and compared their expression with adjacent normal esophageal mucosa. No significant expression of ER $\alpha$ was found in EAC, suggesting that ER $\alpha$ is unlikely to be involved in the growth of this cancer.

Overall, most studies that have evaluated EAC suggest a prognostic value for ER $\beta$. Unfortunately, these clinical reports have not yet been supported by in vitro studies with EAC cells. The few in vitro studies that have addressed the role of estrogens in the modulation of esophageal tumor cell proliferation were performed using ESCC cells $(88,89)$. Estrogens were shown to exert anti-proliferative action on human ESCC cells likely through ER-Ca ${ }^{2+}$ signaling pathway. However, ESCC and EAC are two biologically distinct tumors, so estrogen responsiveness in ESCC derived cell lines does not necessarily mean that cell lines from EAC will respond. To further explore this possibility, similar experiments need to be performed using EAC derived cell lines.

Several studies have reported that ERs could be prognostic biomarkers in ESCC with controversial results. Nozoe et al. (90) and Zhang et al. (91) reported that ER $\alpha$ positive and ER $\beta$-negative expression associate with poor OS in patients with ESCC patients. Whereas, Dong et al. (92) and Zuguchi et al. (93) suggested that upregulation of ER $\beta$ and downregulation of $\mathrm{ER} \alpha$ predict unfavorable prognosis in ESCC.

In 2019, Zhang et al. performed a meta-analysis to better assess the prognostic value of ER $\alpha$ and ER $\beta$ expression in gastroesophageal cancer to further identify novel therapeutic approaches (94).

The study included 7 articles with 11 cohort studies for a total of 1,874 patients. The cancer types included in the studies were ESCC and GCA (gastric adenocarcinoma). Results revealed that high ER $\alpha$ expression correlates with a worse prognosis whereas ER $\beta$ with a better OS.

Overexpression of $\mathrm{ER} \alpha$ in cancer tissues predicted worst OS and poor tumor differentiation. Furthermore, based on data obtained analyzing tumor tissue biopsies from patients, the correlation between high expression of ER $\beta$, better OS and tumor differentiation was statistically significant.

Although this study reported that the expression of both $\mathrm{ER} \alpha$ and $\mathrm{ER} \beta$ was linked to gastroesophageal cancer prognosis and differentiation, there were some limitations. First, the quality of included studies was done with selection bias due to the deletion of some unqualified literature. Furthermore, the screened literature was only in English and Chinese, which significate that included data could not represent the entire patient population.

\section{Thymus cancers}

\section{Subtypes: thymoma, thymic carcinoma}

Thymomas and thymic carcinomas are rare tumors that develop in cells that cover the outside surface of the thymus, a small organ located in the upper chest, under the breastbone, part of the lymphatic system.

Controversy exists regarding the expression of ERs in thymic tumors. In a study performed in 2003, the immunohistochemical localization of $\mathrm{ER} \alpha$ and $\mathrm{ER} \beta$ was examined and correlated with various clinicopathological parameters in 132 human thymomas (95). Immunoreactivity 
for ERs was detected in the nuclei of thymoma epithelial cells. The percentage of immune-positive samples and the $\mathrm{H}$-score values (mean +/- SD) were $66 \%$ and $85.8+/-80.2$ for $\mathrm{ER} \alpha$ and $7 \%$ and $7.2+/-8.7$ for ER $\beta$, respectively. ER $\alpha$ immunoreactivity was inversely correlated with tumor size, clinical stage, and Ki-67 labeling index, and significantly associated with better clinical outcomes in thymoma patients. In another study, the production of estrogens was examined in vitro using primary cultures of human thymoma epithelial cells (TEC), while the intratumoral concentration was measured and correlated with clinicopathologic variables and clinical outcomes in 132 patients (96). In accordance with previous data, it was described that estradiol inhibited proliferation of TEC through ER $\alpha$, which suggests that estradiol may be an effective treatment for thymoma, especially for non-resectable tumors. Therefore, in situ estradiol synthesis may play a significant role in the development of thymoma through regulation of cell proliferation.

In contrast with previous data, in 2011, a study correlated the expression of ER $\alpha$ and $\mathrm{ER} \beta$, evaluated by immunohistochemistry, with clinicopathologic factors and OS in a series of 140 thymic epithelial tumors (97). ER $\beta$ was found to be highly expressed in thymomas and thymic carcinomas (76.4\%), whereas rates of ER $\alpha$ were low (13.6\%). Significant correlations between ER $\alpha$ expression and tumor size and between ER $\beta$ expression and tumor stage were described.

Finally, in a study published in 2015 the expression levels of the ER $\beta 5$ variant were analyzed in a set of tissue microarrays from a cohort of patients with thymic tumors $(\mathrm{n}=103)$ by immunohistochemistry (98). The results revealed that ER $\beta 5$ was overexpressed and predominantly located in the cytoplasm (cER $\beta 5$ ) of thymic tumors. Moreover, researchers identified statistically significant differences between cER $\beta 5$ expression and histologic subtype and stage of thymic tumors. Notably, a negative correlation between high expression of cER $\beta 5$ and tumor stage was identified, indicating that cER $\beta 5$ may inhibit thymic tumor progression. Further analysis of data revealed that high expression of cER $\beta 5$ was a significant prognostic factor in patients with thymic tumors. In addition, these results indicated that high cER $\beta 5$ expression was correlated with longer OS and PFS of patients.

The results presented here indicate that the underlying mechanism of estrogen action in thymic tumors may be complex and further investigations are needed.

\section{Summary}

In addition to the well-known drivers of thoracic malignancies, epidemiological evidences, preclinical in vitro and in vivo studies, and recent data obtained from clinical studies, support estrogen and ERs as key factors that affect tumor prognosis and response to therapy.

However, in literature, there are many conflicting results that need to be addressed, which include: standardized measurements of ERs expression, role of different estrogen and ERs isoforms in cancer cell proliferation and invasion, pathways involved in their interactions with other mediators, and mechanisms that underlie the controversy in the effect of HRT.

One of the problems in immunohistochemical staining for ERs is that these proteins when bound to ligands translocate into the nucleus. To detect nuclear proteins, the nucleus has to be made permeable to antibodies and this is usually done by a brief incubation with $0.5 \%$ triton; however, in making the nucleus permeable antigens from the cytoplasm can be lost (99).

Recent reviews have addressed different problems caused by the use of ER $\alpha$ and ER $\beta$ antibodies, which have caused confusion in the literature $(100,101)$.

A problem is that antibodies raised against the $\mathrm{N}$-terminus of ER $\beta$ expressed in E. coli, are efficient in recognizing ER $\beta$ expressed in E. coli, but they do not work well when used in immunohistochemistry experiments on human tissues. This is probably due to post transcriptional modifications of serine and threonine residues in the $\mathrm{N}$-terminus of ER $\beta$ that mask the epitopes which the antibodies recognize. In any case, when producing an antibody, care should be taken to use epitopes that do not include threonine, serine or tyrosine residues which can be phosphorylated.

A further problem is the expression of ER $\beta$ splice variants in human tissues. These variants have modified C-termini that cannot be recognized by antibodies raised against the $\mathrm{C}$-terminus of ER $\beta 1$. Antibodies raised against the $\mathrm{N}$-terminus of ER $\beta$ are useful to evaluate ER $\beta 1$ and all of its splice variants.

Down side of use of these antibodies raised against the $\mathrm{N}$-terminus of ER $\beta$ is that they led to the wrong conclusion that ER $\beta 1$ is expressed in cancers when, in fact, what is being measured are the splice variants of $\operatorname{ER} \beta$ (99).

In addition, several of the antibodies currently used for the detection of ER $\alpha$ do not detect the ER $\alpha$ variants (102). 
Given that there are multiple isoforms of ER $\alpha$ and ER $\beta$ with different localization and functions, it may be necessary to explore more in detail which isoforms are expressed in thoracic malignancies specimens. As shown in Figure 1, only one of the ER $\alpha$ isoforms has been described in NSCLC, one of the ER $\beta$ in TC and three in EAC. Detection of these isoforms may not only help better judge the prognosis of cancer patients, but also guide endocrine therapy and/or other emerging therapeutics.

Preclinical studies, mainly performed in NSCLC, describe the role of ERs in modulating different signaling pathways in tumor cells. Computational models could facilitate a more comprehensive understanding of the complex signaling networks composed of genes and pathways influenced by ERs.

Furthermore, while it has been established that lung tumor cells can be regulated by estrogens, their role in the regulation of tumor associated stroma and pro- and antitumor immune cells is now emerging. Unraveling the role of estrogens in lung tumor microenvironment carries important implications for clinical translation and would provide the rationale for testing combinations of ERs blockers with immunotherapy drugs.

However, even though ER functions are highly cellcontext specific and it is difficult to propose a unified scheme for estrogen signaling, on the basis of above reported data, it appears clear that sex hormones influence pathophysiology, clinical signs, outcome and therapy of the different thoracic malignancies. What emerges from studies is that sex and menopausal status are important stratification factors that should be taken into account in all cancer preclinical studies and clinical trials for a better understanding of biological differences between men and women and pivotal for improving targeted therapies.

It has been recognized that gender differences in drug pharmacokinetics and pharmacodynamics play a key role in drug efficacy and safety profile (103).

Unfortunately, during the last decades, gender unbalance emerged in both animal studies and clinical trials. In fact, most of epidemiological and clinical studies report results in only one sex. This means that results obtained only in men were transferred to the entire population, including women (104). Moreover, due to the retrospective nature of these studies, numerous confounding factors (age, stage of disease, co-morbidity etc.) may have influenced results.

In summary, gender-related oncology needs to better clarify the molecular basis underlying gender differences in patient outcomes and response to therapy. The broad understanding of the biological mechanisms responsible for sex-specific differences may yield improvements in cancer management and in the development of personalized therapeutic strategies. This new dimension of oncology requires additional investment in research and, most of all, the determination of changing health approaches.

\section{Acknowledgments}

The authors acknowledge for salary support of G.P., B.M. and C.B. the project HERMES "HEreditary Risk in MESothelioma" and Università del Piemonte Orientale (Bando ricerca locale 2016).

Funding: None.

\section{Footnote}

Reporting Checklist: The authors have completed the Narrative Review reporting checklist. Available at http:// dx.doi.org/10.21037/jtd-20-2277

Conflicts of Interest: All authors have completed the ICMJE uniform disclosure form (available at http://dx.doi. org/10.21037/jtd-20-2277). The authors have no conflicts of interest to declare.

Ethical Statement: The authors are accountable for all aspects of the work in ensuring that questions related to the accuracy or integrity of any part of the work are appropriately investigated and resolved.

Open Access Statement: This is an Open Access article distributed in accordance with the Creative Commons Attribution-NonCommercial-NoDerivs 4.0 International License (CC BY-NC-ND 4.0), which permits the noncommercial replication and distribution of the article with the strict proviso that no changes or edits are made and the original work is properly cited (including links to both the formal publication through the relevant DOI and the license). See: https://creativecommons.org/licenses/by-nc-nd/4.0/.

\section{References}

1. Gabriele L, Buoncervello M, Ascione B, et al. The gender perspective in cancer research and therapy: novel insights and on-going hypotheses. Ann Ist Super Sanità 2016;52:213-22.

2. Micheli A, Ciampichinia R, Oberaignerb W, et al. The 
EUROCARE Working Group. The advantage of women in cancer survival: An analysis of EUROCARE-4 data. Eur J Cancer 2009;45:1017-27.

3. Jirtle RL, Skinner MK. Environmental epigenomics and disease susceptibility. Nat Rev Genet 2007;8:253-62.

4. Kuiper GG, Carlsson B, Grandien J, et al. Comparison of the ligand binding specificity and transcript tissue distribution of estrogen receptors $\alpha$ and $\beta$. Endocrinology 1997;138:863-70.

5. Couse JF, Lindzey J, Grandien K, et al. Tissue distribution and quantitative analysis of estrogen receptor-alpha (ERalpha) and estrogen receptor-beta (ERbeta) messenger ribonucleic acid in the wild-type and ERalpha-knockout mouse. Endocrinology 1997;138:4613-21.

6. Rubanyi GM, Freay AD, Kauser K, et al. Vascular estrogen receptors and endothelium-derived nitric oxide production in the mouse aorta. Gender difference and effect of estrogen receptor gene disruption. J Clin Invest 1997;99:2429-37.

7. Patrone C, Cassel TN, Pettersson K, et al. Regulation of postnatal lung development and homeostasis by estrogen receptor $\beta$. Mol Cell Biol 2003;23:8542-52.

8. Nilsson S, Mäkelä S, Treuter E, et al. Mechanisms of estrogen action. Physiol Rev 2001;81:1535-65.

9. Kelly MJ, Levin ER. Rapid actions of plasma membrane estrogen receptors. Trends Endocrinol Metab 2001;12:152-6.

10. Levin ER. Integration of the extranuclear and nuclear actions of estrogen. Mol Endocrinol 2005;19:1951-59.

11. Nilsson S, Koehler KF, Gustafsson JÅ. Development of subtype-selective oestrogen receptor-based therapeutics. Nat Rev Drug Discov 2011;10:778-92.

12. Nilsson S, Gustafsson JÅ. Estrogen receptors: therapies targeted to receptor subtypes. Clin Pharmacol Ther 2011;89:44-55.

13. Flouriot G, Brand H, Denger S, et al. Identification of a new isoform of the human estrogen receptor-alpha (hERalpha) that is encoded by distinct transcripts and that is able to repress hER-alpha activation function 1. EMBO J 2000;19:4688-700.

14. Maaroufi Y, Lacroix M, Lespagnard L, et al. Estrogen receptor of primary breast cancers: evidence for intracellular proteolysis. Breast Cancer Res 2000;2:444-54.

15. Barraille $\mathrm{P}$, Chinestra $\mathrm{P}$, Bayard F, et al. Alternative initiation of translation accounts for a $67 / 45 \mathrm{kDa}$ dimorphism of the human estrogen receptor ERalpha. Biochem Biophys Res Commun 1999;257:84-8.

16. Wang Y, Miksicek RJ. Identification of a dominant negative form of the human estrogen receptor. Mol Endocrinol 1991;5:1707-15.

17. Wang $Z$, Zhang $X$, Shen $P$, et al. Identification, cloning, and expression of human estrogen receptor-alpha36, a novel variant of human estrogen receptor-alpha66. Biochem Biophys Res Commun 2005;336:1023-7.

18. Moore JT, McKee DD, Slentz-Kesler K, et al. Cloning and characterization of human estrogen receptor beta isoforms. Biochem Biophys Res Commun 1998;247:75-8.

19. Chu S, Fuller PJ. Identification of a splice variant of the rat estrogen receptor beta gene. Mol Cell Endocrinol 1997;132:195-9.

20. Leygue E, Dotzlaw H, Watson PH, et al. Expression of estrogen receptor beta1, beta2, and beta5 messenger RNAs in human breast tissue. Cancer Res 1999;59:1175-9.

21. Iwao K, Miyoshi Y, Egawa C, et al. Quantitative analysis of estrogen receptor-beta mRNA and its variants in human breast cancers. Int J Cancer 2000;88:733-6.

22. Zappa C, Mousa SA. Non-small cell lung cancer: current treatment and future advances. Transl Lung Cancer Res 2016;5:288-300.

23. Dela Cruz CS, Tanoue LT, Matthay RA. Lung cancer: epidemiology, etiology and prevention. Clin Chest Med 2011;32:605-44.

24. Couraud S, Zalcman G, Milleron B, et al. Lung cancer in never smokers-a review. Eur J Cancer 2012;48:1299-311.

25. Stapelfeld C, Dammann C, Maser E.Sex-specificity in lung cancer risk. Int J Cancer 2020;146:2376-82.

26. Barrera-Rodriguez R, Morales-Fuentes J. Lung cancer in women. Lung Cancer (Auckl) 2012;3:79-89.

27. Gao X, Yue C, Zhuo W, et al. Estrogen receptors promote NSCLC progression by modulating the membrane receptor signaling network: a systems biology perspective. J Transl Med 2019;17:308.

28. Siegfried JM, Hershberger PA, Stabile LP. Estrogen receptor signaling in lung cancer. Semin Oncol 2009;36:524-31.

29. Hsu LH, Chu NM, Kao SH. Estrogen, Estrogen Receptor and Lung Cancer. Int J Mol Sci 2017;18:1713.

30. Wu CT, Chang YL, Shih JY, et al. The significance of estrogen receptor beta in 301 surgically treated nonsmall cell lung cancers. J Thorac Cardiovasc Surg 2005;130:979-86.

31. Skov BG, Fischer BM, Pappot H. Estrogen receptor beta over expression in males with non-small cell lung cancer is associated with better survival. Lung Cancer 2008;59:88-94.

32. Nose N, Sugio K, Oyama T, et al. Association between 
estrogen receptor-beta expression and epidermal growth factor receptor mutation in the postoperative prognosis of adenocarcinoma of the lung. J Clin Oncol 2009;27:411-7.

33. Raso MG, Behrens C, Herynk MH, et al. Immunohistochemical expression of estrogen and progesterone receptors identifies a subset of NSCLCs and correlates with EGFR mutation. Clin Cancer Res 2009; 15:5359-68.

34. Stabile LP, Dacic S, Land SR, et al. Combined analysis of estrogen receptor beta-1 and progesterone receptor expression identifies lung cancer patients with poor outcome. Clin Cancer Res 2011;17:154-64.

35. Rouquette I, Lauwers-Cances V, Allera C, et al. Characteristics of lung cancer in women: Importance of hormonal and growth factors. Lung Cancer 2012;76:280-5.

36. Rades D, Setter C, Dahl O, et al. The prognostic impact of tumor cell expression of estrogen receptoralpha, progesterone receptor, and androgen receptor in patients irradiated for non small cell lung cancer. Cancer 2012;118:157-63.

37. Karlsson C, Helenius G, Fernandes O, et al. Estrogen receptor beta in NSCLC-Prevalence, proliferative influence, prognostic impact and smoking. APMIS 2012;120:451-8.

38. Navaratnam S, Skliris G, Qing G, et al. Differential role of estrogen receptor beta in early versus metastatic non-small cell lung cancer. Horm Cancer 2012;3:93-100.

39. Liu Z, Liao Y, Tang H, et al. The expression of estrogen receptors beta2, 5 identifies and is associated with prognosis in non-small cell lung cancer. Endocrine 2013;44:517-24.

40. Kadota K, Eguchi T, Villena-Vargas J, et al. Nuclear estrogen receptor-alpha expression is an independent predictor of recurrence in male patients with pT1aN0 lung adenocarcinomas, and correlates with regulatory T-cell infiltration. Oncotarget 2015;6:27505-18.

41. Liu CM, Chiu KL, Chen TS, et al. Potential therapeutic benefit of combining gefitinib and tamoxifen for treating advanced lung adenocarcinoma. Biomed Res Int 2015;2015:642041.

42. Omoto Y, Kobayashi Y, Nishida K, et al. Expression, function, and clinical implications of the estrogen receptor beta in human lung cancers. Biochem Biophys Res Commun 2001;285:340-7.

43. Tanaka K, Shimizu K, Kakegawa S, et al. Prognostic significance of aromatase and estrogen receptor beta expression in EGFR wild-type lung adenocarcinoma. Am J
Transl Res 2016;8:81-97.

44. Baik CS, Eaton KD. Estrogen signaling in lung cancer: An opportunity for novel therapy. Cancers 2012;4:969-88.

45. Skjefstad K, Grindstad T, Khanehkenari MR, et al. Prognostic relevance of estrogen receptor alpha, beta and aromatase expression in non-small cell lung cancer. Steroids 2016;113:5-13.

46. Li W, Tse LA, Wang F. Prognostic value of estrogen receptors mRNA expression in non-small cell lung cancer: A systematic review and meta-analysis. Steroids 2015;104:129-36.

47. Ma L, Zhan P, Liu Y, et al. Prognostic value of the expression of estrogen receptor beta in patients with non-small cell lung cancer: A meta-analysis. Transl Lung Cancer Res 2016;5:202-7.

48. Wang Z, Li Z, Ding X, et al. ERbeta localization influenced outcomes of EGFR-TKI treatment in NSCLC patients with EGFR mutations. Sci Rep 2015;5:11392.

49. Kawai H. Estrogen Receptors as the Novel Therapeutic Biomarker in Non-Small Cell Lung. Cancer World J Clin Oncol 2014;5:1020-7.

50. Pelekanou V, Anastasiou E, Bakogeorgou E, et al. Estrogen Receptor-Alpha Isoforms Are the Main Estrogen Receptors Expressed in Non-Small Cell Lung Carcinoma. Steroids 2019;142:65-76.

51. Gao X, Cai Y, Wang Z, et al. Estrogen receptors promote NSCLC progression by modulating the membrane receptor signaling network: a systems biology perspective. J Transl Med 2019;17:308.

52. Huang L, Liu T, Ji H, et al. Expression Pattern of Estrogen Receptor $\beta$ and Its Correlation With Multidrug Resistance in Non-Small Cell Lung Cancer. Neoplasma 2019;66:847-57.

53. Caetano MS, Zhang H, Cumpian AM, et al. IL6 Blockade Reprograms the Lung Tumor Microenvironment to Limit the Development and Progression of K-ras-Mutant Lung Cancer. Cancer Res 2016;76:3189-99.

54. Smida T, Bruno TC, Stabile LP. Influence of estrogen on the NSCLC microenvironment: a comprehensive picture and clinical implications. Front Oncol 2020;10:137.

55. Ganti AK, Sahmoun AE, Panwalkar AW, et al. Hormone replacement therapy is associated with decreased survival in women with lung cancer. J Clin Oncol 2006;24:59-63.

56. Liu Y, Inoue M, Sobue T, et al. Reproductive factors, hormone use and the risk of lung cancer among middle-aged never-smoking Japanese women: A largescale population-based cohort study. Int J Cancer 2005;117:662-6. 
57. Niikawa H, Suzuki T, Miki Y, et al. Intratumoral estrogens and estrogen receptors in human non-small cell lung carcinoma. Clin Cancer Res 2008;14:4417-26.

58. Zhang G, Yanamala N, Lathrop KL, et al. Ligandindependent antiapoptotic function of estrogen receptor-beta in lung cancer cells. Mol Endocrinol 2010;24:1737-47.

59. Mah V, Marquez D, Alavi M, et al. Expression levels of estrogen receptor beta in conjunction with aromatase predict survival in non-small cell lung cancer. Lung Cancer 2011;74:318-25.

60. Chlebowski RT, Schwartz AG, Wakelee H, et al. Women's Health Initiative Investigators. Oestrogen plus progestin and lung cancer in postmenopausal women (Women's Health Initiative trial): A post-hoc analysis of a randomised controlled trial. Lancet 2009;374:1243-51.

61. Slatore CG, Chien JW, Au DH, et al. Lung cancer and hormone replacement therapy: Association in the vitamins and lifestyle study. J Clin Oncol 2010;28:1540-6.

62. Schabath MB, Wu X, Vassilopoulou-Sellin R, et al. Hormone replacement therapy and lung cancer risk: A case-control analysis. Clin Cancer Res 2004;10:113-23.

63. Schwartz AG, Wenzlaff AS, Prysak GM, et al. Reproductive factors, hormone use, estrogen receptor expression and risk of non small-cell lung cancer in women. J Clin Oncol 2007;25:5785-92.

64. Huang B, Carloss H, Wyatt SW, et al. Hormone replacement therapy and survival in lung cancer in postmenopausal women in a rural population. Cancer 2009; 115:4167-75.

65. Ayeni O, Robinson A. Hormone replacement therapy and outcomes for women with non-small-cell lung cancer: Can an association be confirmed? Curr Oncol 2009;16:21-5.

66. Chlebowski RT, Anderson GL, Manson J.E, et al. Lung cancer among postmenopausal women treated with estrogen alone in the Women's Health Initiative randomized trial. J Natl Cancer Inst 2010;102:1413-21.

67. Titan AL, He H, Lui N, et al. The influence of hormone replacement therapy on lung cancer incidence and mortality. J Thorac Cardiovasc Surg 2020;159:1546-56.e4.

68. Sher T, Dy GK, Adjei AA. Small cell lung cancer. Mayo Clin Proc 2008;83:355-67.

69. Duma N, Ho TP, Durani U, et al. Exploring sex differences in small cell lung cancer: Is this a hormonal issue? J Clin Oncol 2019:37:e20077.

70. Yang X, Xue L, Liu Y, et al. Clinicopathological and Prognostic Significance of ER $\alpha$ and ER $\beta$ Expression in Lung Carcinomas: A Tissue Microarray Study. Zhonghua
Zhong Liu Za Zhi 2013;35:678-83.

71. Zeng J, Wang B, Chen G. Impact of sex hormone on small cell lung carcinoma xenograft model in nude mouse. Int J Clin Exp Med 2016;9:20165-70.

72. Vivero M, Bueno R, Chirieac LR. Clinicopathologic and genetic characteristics of young patients with pleural diffuse malignant mesothelioma. Mod Pathol 2018;31:122-31.

73. Marinaccio A, Corfiati M, Binazzi A, et al. The epidemiology of malignant mesothelioma in women: gender differences and modalities of asbestos exposure. Occup Environ Med 2018;75:254-62.

74. Barsky AR, Ahern CA, Venigalla S, et al. Genderbased disparities in receipt of care and survival in malignant pleural mesothelioma. Clin Lung Cancer 2020;21:e583-e591.

75. Pinton G, Brunelli E, Murer B, et al. Estrogen ReceptorBeta Affects the Prognosis of Human Malignant Mesothelioma. Cancer Res 2009;69:4598-604.

76. Pinton G, Moro L. Expression and Therapeutic Significance of Estrogen Receptor $\beta$ in Malignant Pleural Mesothelioma. Future Sci OA 2017;3:FSO175.

77. Manente AG, Valenti D, Pinton G, et al. Estrogen receptor $\beta$ activation impairs mitochondrial oxidative metabolism and affects malignant mesothelioma cell growth in vitro and in vivo. Oncogenesis 2013;2:e72.

78. Pinton G, Manente AG, Daga A, et al. Agonist activation of estrogen receptor beta $(\mathrm{ER} \beta)$ sensitizes malignant pleural mesothelioma cells to cisplatin cytotoxicity. Mol Cancer 2014;13:227.

79. Rodríguez-Cid JR, García-Acevedo O, BenjaminContreras J, et al. Expression of Estrogen Receptor Beta (ER $\beta$ ) and Its Prognostic Value in Pleural Mesothelioma. J Thorac Dis 2019;11:1456-64.

80. Rustgi AK, El-serag HB. Esophageal carcinoma. N Engl J Med 2014;371:2499-509.

81. Arnold M, Soerjomataram I, Ferlay J, et al. Global incidence of oesophageal cancer by histological subtype in 2012. Gut 2015;64:381-7.

82. Lepage C, Drouillard A, Jouve J, et al. Epidemiology and risk factors for Oesophageal adenocarcinoma. Dig Liver Dis 2013;45:625-9.

83. Kamangar F, Chow WH, Abnet CC, et al. Environmental Causes of Esophageal Cancer. Gastroenterol. Clin North Am 2009;38:27-57.

84. Xie SH, Lagergren J. The Male Predominance in Esophageal Adenocarcinoma. Clin Gastroenterol Hepatol 2016;14:338-47.e1. 
85. Yang H, Sukocheva OA, Hussey DJ, et al. Estrogen, male dominance and esophageal adenocarcinoma: Is there a link? World J Gastroenterol 2012;18:393-400.

86. Liu L, Chirala M, Younes M. Expression of estrogen receptor-beta isoforms in Barrett's metaplasia, dysplasia and esophageal adenocarcinoma. Anticancer Res 2004;24:2919-24.

87. Kalayarasan R, Ananthakrishnan N, Kate V, et al. Estrogen and progesterone receptors in esophageal carcinoma. Dis Esophagus 2008;21:298-303.

88. Ueo H, Matsuoka H, Sugimachi K, et al. Inhibitory effects of estrogen on the growth of a human esophageal carcinoma cell line. Cancer Res 1990;50:7212-5.

89. Zhang Z, He Q, Fu S, et al. Estrogen receptors in regulating cell proliferation in esophageal squamous cell carcinoma: involvement of intracellular $\mathrm{Ca} 2+$ signaling. Pathol Oncol Res 2017;23:329-34.

90. Nozoe T, Oyama T, Takenoyama M, et al. Significance of immunohistochemical expression of estrogen receptors $\alpha$ and $\beta$ in squamous cell carcinoma of the esophagus. Clin Cancer Res 2007;13:4046-50.

91. Zhang D, Ku JW, Liu R, et al. Characterization of serum estradiol level and tissue estrogen receptor immunostaining with clinical response and reproductive factor changes in Chinese female patients with esophageal squamous cell carcinoma. Biomed Pharmacother 2017;93:879-84.

92. Dong J, Jiang SW, Niu Y, et al. Expressions of estrogen receptor $\alpha$ and $\beta$ in esophageal squamous cell carcinoma. Oncol Rep 2013;30:2771-6.

93. Zuguchi M, Miki Y, Onodera Y, et al. Estrogen receptor $\alpha$ and $\beta$ in esophageal squamous cell carcinoma. Cancer Sci 2012;103:1348-55.

94. Zhang D, Ku J, Yi Y., et al. The prognostic values of estrogen receptor alpha and beta in patients with

Cite this article as: Pinton G, Manzotti B, Balzano C, Moro L. Expression and clinical implications of estrogen receptors in thoracic malignancies: a narrative review. J Thorac Dis 2021;13(3):1851-1863. doi: 10.21037/jtd-20-2277 gastroesophageal cancer A meta-analysis. Medicine (Baltimore) 2019;98:e17954.

95. Ishibashi H, Suzuki T, Suzuki S, et al. Sex Steroid Hormone Receptors in Human Thymoma. J Clin Endocrinol Metab 2003;88:2309-17.

96. Ishibashi H, Suzuki T, Suzuki S, et al. Estrogen Inhibits Cell Proliferation Through in Situ Production in Human Thymoma. Clin Cancer Res 2005;11:6495-504.

97. Mimae T, Tsuta K, Takahashi F, et al. Steroid Receptor Expression in Thymomas and Thymic Carcinomas. Cancer 2011;117:4396-405.

98. Li SY, Wang YX, Wang L, et al. Cytoplasm estrogen receptor $\beta 5$ as an improved prognostic factor in thymoma and thymic carcinoma progression. Oncol Lett 2015;10:2341-6.

99. Gustafsson JA, Strom A, Warner M. Update on ERbeta. J Steroid Biochem Mol Biol 2019;191:105312.

100.Nelson AW, Groen AJ, Miller JL, et al. Comprehensive assessment of estrogen receptor beta antibodies in cancer cell line models and tissue reveals critical limitations in reagent specificity. Mol Cell Endocrinol 2017;440:138-50.

101. Andersson S, Sundberg M, Pristovsek N, et al. Insufficient antibody validation challenges oestrogen receptor beta research. Nat Commun 2017;8:15840.

102. Chantalat E, Boudou F, Laurell H, et al. The AF-1deficient estrogen receptor ER $\alpha 46$ isoform is frequently expressed in human breast tumors. Breast Cancer Res 2016;18:123.

103. Soldin OP, Mattison DR. Sex Differences in Pharmacokinetics and Pharmacodynamics. Clin Pharmacokinet 2009; 48:143-57.

104. Westergaard D, Moseley P, Sørup FKH, et al. Populationwide analysis of differences in disease progression patterns in men and women. Nat Commun 2019;10:666. 